\title{
Deficiency of the Autologous Mixed Lymphocyte Reaction in Patients with Primary Biliary Cirrhosis
}

\author{
Stephen P. James, Charles O. Elson, Jeanne G. Waggoner, E. Anthony Jones, \\ and Warren Strober, Liver Diseases Section, Digestive Diseases Branch, \\ National Institute of Arthritis, Metabolism and Digestive Diseases and \\ the Metabolism Branch, National Cancer Institute, National Institutes of Health, \\ Bethesda, Maryland 20205
}

\begin{abstract}
A B S T R A C T In this study we show that patients with primary biliary cirrhosis (PCB) have a marked deficiency in the ability to generate an autologous mixed lymphocyte reaction (AMLR) but have a normal ability to generate an allogeneic mixed lymphocyte reaction (MLR). This deficiency is not due to differences in the time-course of the proliferative response or to an altered response to variable numbers of stimulator cells. The deficiency was consistently found irrespective of the methods used to isolate autologous stimulator cells. Both responder cells and stimulator cells obtained from patients with PBC were similar to normal cells in their ability to generate an MLR in allogeneic normal human serum. In addition, serum from patients with PBC inhibited the ability of normal lymphocytes to generate both the AMLR and MLR to a similar degree, suggesting that the defect of the AMLR in PBC is not due to a serum factor. It has been shown that the responder cell population in the AMLR contains a subpopulation of cells that mediate suppression. Therefore, it is possible that the deficiency of the AMLR may be related to previously described abnormalities of suppressor function in patients with PBC.
\end{abstract}

\section{INTRODUCTION}

The proliferation of normal human $\mathrm{T}$ cells in response to autologous non-T peripheral blood mononuclear cells, known as the autologous mixed lymphocyte reaction (AMLR), ${ }^{1}$ may be involved in the regulation of immune responses $(1,2)$. The cells responding in this reaction demonstrate immunological memory and specificity (3). Although the responder cells in

Received for publication 19 March 1980 and in revised form 15 July 1980.

${ }^{1}$ Abbreviations used in this paper: AMLR, autologous mixed lymphocyte reaction; Con A, concanavalin A; MLR, mixed lymphocyte reaction; PBC, primary biliary cirrhosis; SLE, systemic lupus erythematosus; SRBC, sheep erythrocytes. the AMLR are not cytotoxic for stimulating $B$ cells or B lymphoid cell lines (4), the responder cells may have cytotoxic potential against lipopolysaccharidestimulated autologous target cells (5). Furthermore, it has been shown that cells proliferating in the AMLR may suppress proliferative and cytotoxic responses in secondary cultures (6), and that the T cell subpopulation responding in the AMLR is enriched with cells that have the potential of becoming suppressor cells when activated by concanavalin A (Con A) (7). Thus, the decreased generation of suppressor $\mathrm{T}$ cells $(8-10)$ and the deficiency of the AMLR (11-13), which have been found both in patients with systemic lupus erythematosus (SLE) and NZB mice, may be closely related abnormalities.

Recently, we have found that patients with primary biliary cirrhosis (PBC), a disease characterized by inflammatory necrosis of bile ducts and multiple immunological defects, have defective regulation of pokeweed mitogen-induced immunoglobulin synthesis (14). In particular, $T$ cells from patients with PBC do not inhibit immunoglobulin synthesis by autologous $B$ cells at high $T$ to $B$ cell ratios (10:1). Suppression of proliferative responses by Con A activated cells is also deficient in patients with PBC $(15,16)$. The studies described here demonstrate that patients with PBC also have an impaired capacity to mediate an AMLR.

\section{METHODS}

Patients studied. 10 patients with PBC were studied at the Clinical Center of the National Institutes of Health. Informed consent was obtained from each patient. The study protocol had been approved by the National Institute of Arthritis, Metabolism and Digestive Diseases Clinical Research Subpanel. Each patient had typical clinical, serum biochemical, and serological features of PBC. In addition, liver biopsy from each patient showed histologic features compatible with PBC. Patients ranged in age from 39 to $66 \mathrm{yr}$, and one patient was male. Two patients had the sicca 
syndrome, but no patient had any other significant illness. One patient was taking D-penicillamine at the time of study. None of the other patients were taking antiinflammatory medications. 10 normal laboratory personnel, ranging in age from 31 to $47 \mathrm{yr}$, served as control subjects. In addition, three patients with idiopathic sclerosing cholangitis were studied as liver disease controls.

Cell preparations. Mononuclear cells were isolated from fresh heparinized venous blood by Ficoll-Hypaque (Lymphocyte Separation Medium, Bionetics Laboratory Products, Litton Bionetics, Inc., Kensington, Md.) density gradient centrifugation. In some experiments, mononuclear cells were separated into $\mathrm{T}$ and non- $\mathrm{T}$ fractions using Sephadex anti$\left(\mathrm{Fab}^{\prime}\right)_{2}$ immunoabsorbant affinity columns as previously described (14). In brief, mononuclear cells were passed over columns containing Sephadex G-200 to which purified rabbit anti-human $\left(\mathrm{Fab}^{\prime}\right)_{2}$ had been covalently bound. 60$80 \%$ of the cells in the first fraction eluted from the column formed rosettes with sheep erythrocytes (SRBC). Less than $1 \%$ were $\mathrm{B}$ cells as determined by staining with fluoresceinated anti-human light chain antibody $\left(\left[\mathrm{Fab}^{\prime}\right]_{2}\right.$, prepared in our laboratory) and $<1 \%$ of the cells were monocytes, as determined by their ability to ingest latex beads. This $T$ cell enriched fraction was used as the responder cell fraction in one-way mixed lymphocyte reactions. A non- $T$ cell enriched fraction was eluted from the columns using medium supplemented with human gamma globulin (Cohn fraction II, Miles Laboratories, Inc., Elkhart, Ind.). Of the cells in this fraction, on the average $45 \%$ were $\mathrm{B}$ cells, $40 \%$ were monocytes, and $<1 \% \mathrm{~T}$ cells (SRBC rosette-forming cells). The composition of these cell fractions was similar for patients and normal subjects.

In some experiments, mononuclear cells were separated into $T$ and non- $T$ cell fractions by the formation of spontaneous SRBC rosettes overnight at $4^{\circ} \mathrm{C}$, followed by centrifugation of the mixture over Ficoll-Hypaque and lysis of the rosettes with ammonium chloride buffer. In other experiments, as indicated below, stimulator cell fractions were depleted of cells that were adherent to plastic petri dishes. In yet other experiments, monocytes were isolated using the method of Beale et al. (17). In brief, mononuclear cells were passed over a column of Sephadex G-10. Nonadherent cells were eluted with $100 \mathrm{~cm}^{3}$ of warm RPMI-1640 containing $20 \%$ fetal calf serum; this fraction was separated into $\mathrm{T}$ and non-T cell enriched fractions by formation of SRBC rosettes as described above. Adherent cells were removed from G-10 columns by transferring the column beads to medium without fetal calf serum, vigorous vortexing of the beads, and allowing the beads to sediment in an ice bath. This fraction was incubated overnight at $37^{\circ} \mathrm{C}$ in glass petri dishes, washed three times with warm medium to remove nonadherent cells, and incubated for $45 \mathrm{~min}$ at $4^{\circ} \mathrm{C}$ with cold phosphate-buffered saline. This cell fraction contained $\sim 90 \%$ esterase positive cells. Stimulator cells were irradiated with 2,500 rad before culture by exposure to a ${ }^{137} \mathrm{Cs}$ source (Gammator M, Isomedix, Inc., Parsippany, N. J.).

Cell cultures and measurement of $\left[{ }^{3} \mathrm{H}\right]$ thymidine incorporation. Cells were cultured in RPMI-1640 (Gibco Laboratories, Grand Island Biological Co., Grand Island, N. Y.) supplemented with $4 \mathrm{mM}$ L-glutamine, $100 \mathrm{U} / \mathrm{ml}$ penicillin, $100 \mu \mathrm{g} / \mathrm{ml}$ streptomycin, and $10 \%$ heat-inactivated human $\mathrm{AB}$ serum. In some experiments, this culture medium was further supplemented with heat-inactivated normal human serum or serum obtained from patients with PBC. Cells were cultured in flat-bottom microtest plates (No. 3040, Falcon Labware, Div. of Becton, Dickinson Co., Oxnard, Calif.) at $37^{\circ} \mathrm{C}$ in a $5 \% \mathrm{CO}_{2}$ humidified atmosphere, using cell concentrations and duration of culture as described below. The final culture volume was $0.2 \mathrm{ml} .4 .5 \mathrm{~h}$ before termination of culture, $0.5 \mu \mathrm{Ci}$ of methyl $-\left[{ }^{3} \mathrm{H}\right]$ thymidine $(6.7 \mathrm{Ci} / \mathrm{mM}$ sp act, New England Nuclear, Boston, Mass.) was added to each culture. Samples were harvested using an automated sample harvester (Mash II, Microbiological Associates, Walkersville, Md.) and counted in a liquid scintillation counter. The number of disintegrations per minute per sample was calculated using internal standards. Cell cultures were performed in multiples of six. Geometric mean values $(x / \div$ SEM) were determined for appropriate groups of data, and the significance of differences between groups was determined using the Mann-Whitney test.

\section{RESULTS}

Comparison of the AMLR and MLR in patients with $P B C$ and normal subjects. In our initial series of experiments, we determined values for the AMLR and the allogeneic MLR in patients with PBC and normal subjects using culture medium containing normal human serum. In preliminary experiments using normal lymphocytes, we found that maximal values for the AMLR occurred when non- $T$ cell fractions eluted from anti-(Fab' $)_{2}$ immunoabsorbant columns and depleted of cells that were adherent to plastic were used as the stimulator cells. These stimulator cells plus responder $\mathrm{T}$ cells were cultured in equal numbers $\left(1 \times 10^{5}\right)$ for $6 \mathrm{~d}$. The geometric mean value for the AMLR in 10 patients with PBC, $1,038 \mathrm{dpm}$, was significantly lower $(P<0.01)$ than that observed in 10 normal individuals, $9,013 \mathrm{dpm}$ (Fig. 1). In contrast, in the MLR the mean response of $\mathrm{T}$ cells from patients with PBC stimulated by normal allogeneic cells (117,993 dpm) was not significantly different from the mean response of normal $\mathrm{T}$ cells to stimulator cells obtained from patients with PBC $(102,434 \mathrm{dpm})$ (Fig. 1). In addition, in the MLR the response of normal $T$ cells to allogeneic normal stimulator cells $(130,307$ $\mathrm{dpm}$ ) was similar to the response of normal T cells to allogeneic stimulator cells from patients with PBC. Background incorporation of label into $T$ cells cultured alone or in the presence of irradiated $T$ cells was insignificant in each experiment. There was no correlation between the degree of impairment of the AMLR and the severity of disease. In addition, three patients with chronic cholestasis due to idiopathic sclerosing cholangitis had values for the AMLR (mean 6,954 $\times / \div 1.83$ ) that were similar to normal individuals.

Kinetics of proliferation in AMLR and effect of variable number of stimulator cells. The kinetics of the proliferative response in the AMLR and the MLR in three normal individuals and three patients with PBC are shown in Fig. 2. In these experiments, equal numbers of responder and stimulator non- $T$ cells depleted of cells that adhered to plastic were cultured for varying intervals. Maximum $\left[{ }^{3} \mathrm{H}\right]$ thymidine incorporation for both patients and control subjects occurred at $\sim 6 \mathrm{~d}$. Thus, the marked reduction in the AMLR in 


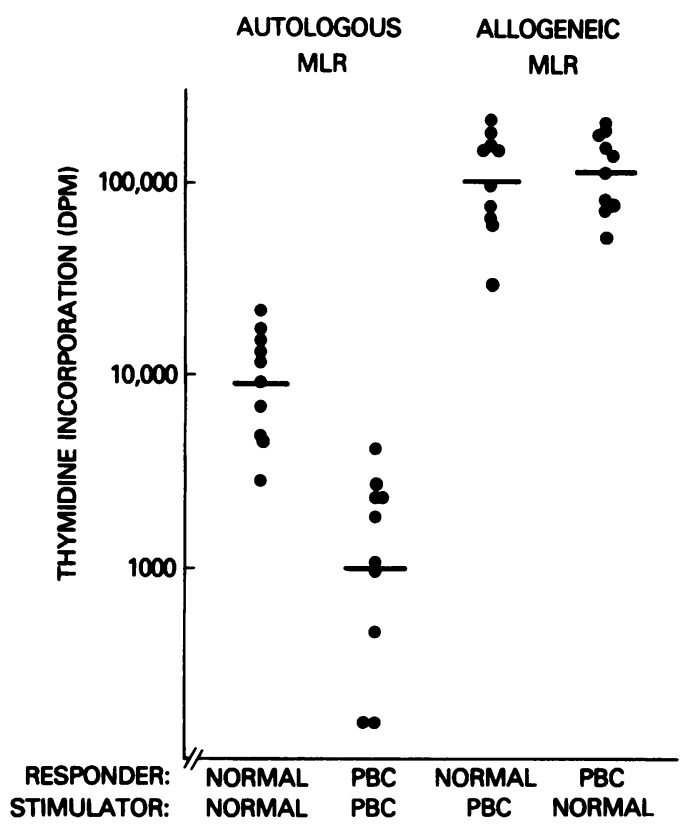

FIGURE 1 [ $\left.{ }^{3} \mathrm{H}\right]$ thymidine incorporation by $\mathrm{T}$ cells from normal subjects and patients with PBC in the AMLR and MLR. Responder $T$ cells and stimulator non- $T$ cells were isolated using anti-( $\left.\mathrm{Fab}^{\prime}\right)_{2}$ immunoabsorbent columns as described in Methods. Responder T cells were obtained from the first fraction eluted from the column. Stimulator cells were eluted from the column with medium supplemented with immunoglobulin, depleted of cells adherent to plastic petri dishes, and irradiated with 2,500 rad. Equal numbers $\left(1 \times 10^{5}\right)$ of responder and stimulator cells were cultured for $6 \mathrm{~d}$ in medium containing $10 \%$ human $\mathrm{AB}$ serum and pulsed with methyl- $\left[{ }^{3} \mathrm{H}\right]$ thymidine $4.5 \mathrm{~h}$ before harvesting. In the MLR, normal responder cells were cultured with PBC stimulator cells, and PBC responder cells were cultured with normal stimulator cells. Cultures were performed in multiples of six. Geometric mean values (DPM) are shown. The AMLR of patients with PBC was significantly $(P<0.01)$ lower than that of normal subjects.

patients with PBC compared with normal individuals could not be attributed to a difference in the timecourse of the proliferative response. The effect of varying the number of stimulator cells on the AMLR in three normal individuals and three patients with $\mathrm{PBC}$ is shown in Fig. 3. In these studies, the proliferative response was measured at $6 \mathrm{~d}$. Cultures of cells from both patients with PBC and normal subjects showed a progressive increase in the AMLR and MLR with increasing number of stimulator cells. However, for a given number of stimulator cells, the magnitude of the response was lower in patients with $\mathrm{PBC}$ than in normal individuals. Thus, the reduction of the AMLR in patients with PBC cannot be ascribed to an abnormal stimulator cell dose effect.

Effect of different methods of preparation of stimulator cells on AMLR in PBC. The decreased AMLR in patients with PBC might be due to selective

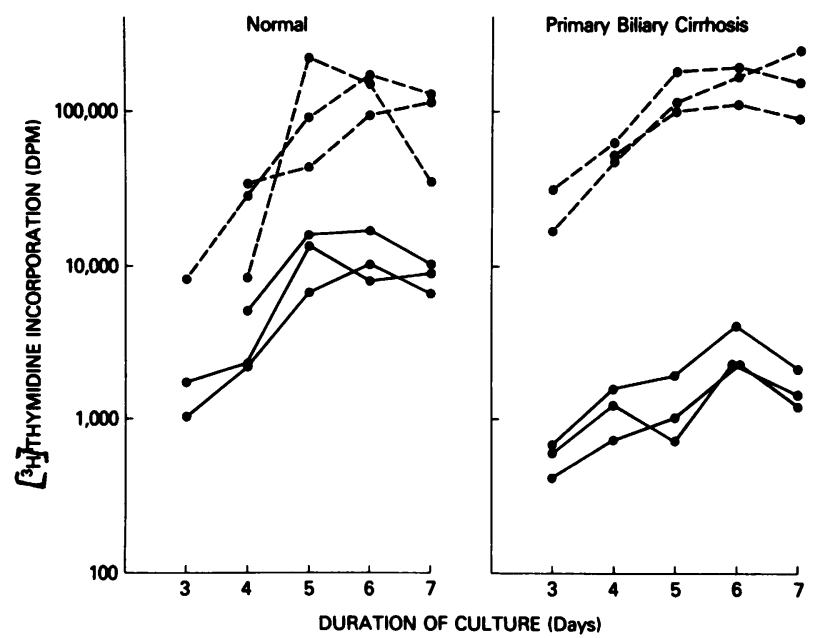

FIGURE $2\left[{ }^{3} \mathrm{H}\right]$ Thymidine incorporation (disintegrations per minute) by $1 \times 10^{5}$ responder T cells in the AMLR (-) and MLR (----) was determined at varying intervals using 1 $\times 10^{5}$ irradiated stimulator cells. Stimulator cells were isolated as in Fig. 1. Plotted values represent geometric means of six replicate cultures, using cells obtained from three normal individuals and three patients with PBC.

depletion from the non- $T$ cell fraction of a stimulator subpopulation as a result of the method used to isolate the non-T fraction described above. Alternatively, the decreased AMLR in PBC patients might be due to the presence of cells within the non-T stimulator cell population that inhibit the AMLR. To investigate these possibilities, we used several different cell fractions as stimulator cells in the AMLR. As shown in Table I (experiments 1 and 2), the stimulatory capacity of PBC non-T cells was enhanced by preincubation of the stimulating cells on plastic; however, the increase was similar to the increase seen in normal individuals. When mononuclear cells were fractionated by SRBC rosette formation (Table I, experiment 3), the AMLR was also deficient in patients with PBC. Finally, when purified monocytes were used as stimulator cells (Table I, experiment 4) the magnitude of the response in patients with $\mathrm{PBC}$ was still lower than in normal subjects, although purified monocytes stimulated a greater AMLR response than other cell populations. These results indicate that the AMLR is consistently deficient in patients with PBC irrespective of the method of cell preparation. It should also be noted that non-T cells from patients with PBC were equivalent to normal non-T cells in their ability to stimulate an MLR with normal $T$ cells, a finding that suggests that the stimulator cell fractions from patients with PBC do not contain an inhibitor of proliferative responses.

Effect of sera from patients with $P B C$ on AMLR and MLR. In the experiments described above, cells were washed multiple times before culture in medium containing normal human $\mathrm{AB}$ serum. The fact that 


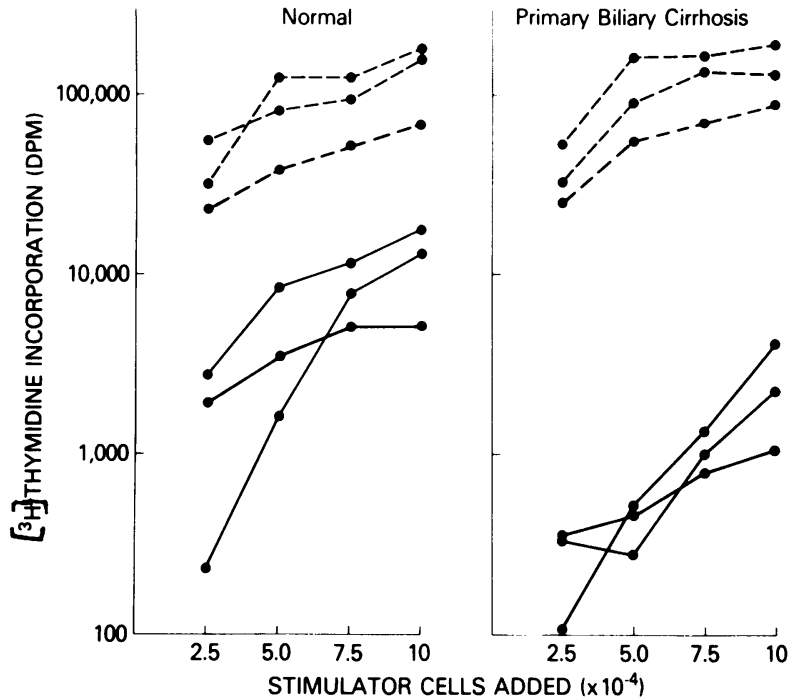

FIGURE $3\left[{ }^{3} \mathrm{H}\right]$ Thymidine incorporation (disintegrations per minute) by $1 \times 10^{5}$ responder T cells in the AMLR (-) or the MLR (-----) using variable numbers of irradiated stimulator cells, isolated as in Fig. 1. Values plotted represent geometric means of six replicate cultures of cells obtained from three normal individuals and three patients with PBC.

stimulator cells obtained from PBC patients generated a normal MLR response by normal $T$ cells, and the fact that PBC T-cells had a normal MLR response with normal stimulator cells, suggests that the diminished
AMLR in PBC is not due to the presence of serum inhibitory factors contaminating the cell fractions. To investigate this possibility further, the AMLR and MLR of normal lymphocytes were measured in the presence of medium containing $10 \%$ normal serum to which was added either sera from eight patients with $\mathrm{PBC}$ or eight normal individuals. In the presence of serum from patients with $\mathrm{PBC}$, mean values for the AMLR and MLR of normal lymphocytes were significantly lower than corresponding values for the AMLR and MLR observed in normal allogeneic serum (Table II). However, the extent to which the AMLR and MLR were reduced by serum from other patients with $\mathrm{PBC}$ was similar. Since these experiments were carried out in medium which contained normal serum, the diminished incorporation of thymidine is not due simply to the inability of PBC sera to support the MLR or AMLR. These results demonstrate that although serum from patients with PBC may have an inhibitory effect on proliferative responses, the inhibitory effect is not specific for the normal AMLR.

The effect of the same normal and PBC sera on the AMLR and MLR of lymphocytes obtained from a patient with PBC was also determined. When $10 \%$ normal serum was added to the culture medium, the mean AMLR was $2,420 \mathrm{dpm}(\times / \div 1.17, n=8)$, and when $10 \%$ PBC serum was added, the mean AMLR was 574 dpm $(\times / \div 1.37, n=8)$. Similarly, the MLR of the patient with $\mathrm{PBC}$ was $74,267 \mathrm{dpm}(\times / \div 1.03, n=8)$

TABLE I

$\left[{ }^{3} \mathrm{H}\right]$ Thymidine Incorporation (Disintegrations per Minute) by T Cells Stimulated with Different Non-T Fractions

\begin{tabular}{|c|c|c|c|c|c|c|}
\hline \multirow[b]{2}{*}{$\begin{array}{l}\text { Expt. } \\
\text { No. }\end{array}$} & \multirow[b]{2}{*}{ Stimulating cells } & \multirow[b]{2}{*}{ Responder cells } & \multicolumn{2}{|c|}{ PBC } & \multicolumn{2}{|c|}{ Normal } \\
\hline & & & $\begin{array}{l}\text { Autologous } \\
\text { MLR }\end{array}$ & $\begin{array}{l}\text { Allogeneic } \\
\text { MLR }\end{array}$ & $\begin{array}{l}\text { Autologous } \\
\text { MLR }\end{array}$ & $\begin{array}{l}\text { Allogeneic } \\
\text { MLR }\end{array}$ \\
\hline 1 & $\begin{array}{l}\text { Anti- }\left(\mathrm{Fab}^{\prime}\right)_{2} \text { column } \\
\text { adherent }\end{array}$ & $\begin{array}{l}\text { Anti-(Fab' })_{2} \text { column } \\
\text { nonadherent }\end{array}$ & $487(5)$ & $93,912(5)$ & $5,204(9)$ & $99,581(9)$ \\
\hline 2 & $\begin{array}{l}\text { Anti- }\left(\mathrm{Fab} \mathrm{b}^{\prime}\right)_{2} \text { column } \\
\text { adherent, nonadherent } \\
\text { to plastic }\end{array}$ & $\begin{array}{l}\left.\text { Anti-( } \text { Fab }^{\prime}\right)_{2} \text { column } \\
\text { nonadherent }\end{array}$ & $1,038(10)$ & $117,973(10)$ & $9,011(10)$ & $102,434(10)$ \\
\hline 3 & $\begin{array}{l}\text { SRBC nonrosette forming, } \\
\text { nonadherent to plastic }\end{array}$ & SRBC rosette forming & $950(3)$ & $143,870(3)$ & $6,601(3)$ & $104,031(3)$ \\
\hline 4 & $\begin{array}{l}\text { Adherent to Sephadex } \\
\text { G-10, adherent to glass }\end{array}$ & $\begin{array}{l}\text { Nonadherent to Sephadex } \\
\text { G-10, SRBC rosette } \\
\text { forming }\end{array}$ & $12,509(6)$ & $72,673(6)$ & $62,169(6)$ & $39,042(6)$ \\
\hline
\end{tabular}

In experiments No. 1 and No. 2, responder and stimulator cells were isolated using anti-(Fab' $)_{2}$ affinity columns as described in Methods. In experiment No. 2, the column adherent fraction was further depleted of cells adherent to plastic. In experiment No. 3, stimulator and responder cells were isolated by formation of SRBC rosettes as described in Methods, and stimulator cells were further incubated on plastic. In experiment No. 4, monocytes were obtained from Sephadex G-10 columns and incubated on glass petri dishes overnight. Responder cells were obtained from the fraction that was nonadherent to G10, and formed rosettes with SRBC. Stimulator cells were irradiated with 2,500 rad, and cultured for $6 \mathrm{~d}$ with an equal number of responder cells $\left(1 \times 10^{5}\right)$. Values shown are geometric mean $\left[{ }^{3} \mathrm{H}\right]$ thymidine incorporation (disintegrations per minute) in six replicate cultures. Numbers in parentheses indicate the number of patients studied for each experimental condition. 
TABLE II

Effect of Serum on AMLR and MLR of Normal Lymphocytes

\begin{tabular}{lrrrrrrr}
\hline & \multicolumn{3}{c}{ Autologous MLR (dpm) } & & \multicolumn{3}{c}{ Allogeneic MLR (dpm) } \\
\cline { 2 - 4 } \cline { 7 - 9 } \multicolumn{1}{c}{ Serum added } & \multicolumn{1}{c}{$1 \%$} & $5 \%$ & $10 \%$ & & $1 \%$ & $5 \%$ & $10 \%$ \\
\hline Normal (8) & 5,655 & 7,036 & 7,018 & & 52,501 & 63,075 & 76,489 \\
PBC (8) & 3,835 & 2,336 & 2,413 & & 23,427 & 22,669 & 20,044 \\
Percent reduction & 32 & 76 & 66 & & 55 & 64 & 73 \\
\hline
\end{tabular}

Responder T cells from one normal individual and stimulator cells (autologous and from one allogeneic normal donor) were prepared as in Fig. 1. Cells were cultured in medium containing $10 \%$ human $\mathrm{AB}$ serum to which was added 1, 5, or $10 \%$ test serum. Values shown represent geometric mean $\left[{ }^{3} \mathrm{H}\right]$ thymidine incorporation (disintegrations per minute) in four replicate cultures, using test sera from eight normal individuals and eight patients with PBC.

when normal serum was added and 18,048 dpm $(x)$ $\div 1.49, n=8$ ) when PBC serum was added. The AMLR and MLR in the patient with PBC were both reduced by $76 \%$ by addition of $\mathrm{PBC}$ serum. The relative reduction of the AMLR and MLR in the normal individual were similar (66\% for AMLR, 73\% for MLR; Table II). Thus the inhibitory effect of serum from PBC patients does not exhibit selective inhibition of the AMLR generated by lymphocytes obtained from a patient with PBC.

\section{DISCUSSION}

A number of features of $\mathrm{PBC}$ suggest that immunological phenomena may play a role in pathogenesis. These include the presence in serum of autoantibodies such as mitochondrial antibody and smooth muscle antibody, high levels of serum IgM, evidence for accelerated consumption of complement components, abnormal lymphocyte cytotoxic responses (18), and high levels of circulating immune complexes (19). Recently, we have found that patients with PBC have decreased $\mathrm{T}$ cell-mediated inhibition of pokeweed mitogen-induced immunoglobulin synthesis in autologous cultures of $T$ and $B$ cells (14). In addition, recent data suggest that Con A-induced suppressor $\mathrm{T}$ cell activity is reduced in $\operatorname{PBC}(15,16)$. The latter two findings support the hypothesis that abnormal regulation of immune responses may be an important component in the pathogenesis of autoimmune phenomena in $\mathrm{PBC}$.

In the present study, we have defined an additional abnormality of immune response in patients with PBC: cultures containing non-T cells and autologous $T$ cells have a decreased proliferative response in the AMLR, whereas cultures containing non-T cells from patients with PBC and normal $T$ cells have a normal proliferative response in the MLR. Additionally, $T$ cells from patients with $\mathrm{PBC}$ have a normal proliferative response in cultures containing allogeneic non- $T$ cells. This defect does not appear to be due to a difference in the time-course of the proliferative response in patients. Furthermore, the AMLR was not increased to the normal range when stimulator cells were obtained by several different methods, suggesting that the defect is not simply an artifact of the method of cell isolation.

The significance of this abnormality to the pathogenesis of PBC may depend on the role of the AMLR in the regulation of the immune response. The AMLR may result in the stimulation of $\mathrm{T}$ cells which are, at least in part, distinct from the $\mathrm{T}$ cells stimulated in the MLR. Furthermore, it has been shown that $\mathrm{T}$ cells stimulated in the AMLR have suppressor activity (6). Recently, it has been shown that $\mathrm{T}$ cells stimulated in autologous cultures are enriched in cells that can be induced by Con A to become suppressor cells, whereas $\mathrm{T}$ cells stimulated in allogeneic cultures are deficient in cells which can be induced by Con A to become suppressor cells (7). On the basis of these findings, it has been suggested that the AMLR reaction occurs in vivo and can play a role in feedback regulation of the immune response. Thus, an abnormal AMLR may contribute to abnormal regulation of the immune response and hence contribute to autoimmune phenomena seen in PBC.

We have previously shown that although $\mathrm{T}$ cells from patients with PBC have decreased ability to inhibit immunoglobulin synthesis by autologous B cells at high $\mathrm{T}$ to $\mathrm{B}$ cell ratios $(10: 1)$, they retain the ability to inhibit immunoglobulin synthesis by normal allogeneic B cells (14). On the basis of this finding, we have suggested that patients with $\mathrm{PBC}$ may have a decrease in function of the population of $T$ cells that is necessary for suppression in autologous cultures, but that the function of the population of $\mathrm{T}$ cells necessary for suppression in allogeneic cultures is intact in PBC. The finding of a deficiency of the AMLR, but normal MLR, in patients with PBC supports this hypothesis and indicates that a deficiency of the AMLR may be the basis for the defect of suppressor $T$ cell 
function in autologous cultures. Further studies of the nature of the responder cell in the AMLR in patients with $\mathrm{PBC}$ is required to prove this hypothesis.

The mechanism by which a deficiency of the AMLR occurs in PBC is not known. The abnormality might be due to a decreased number of responder cells in the $T$ cell population, to a deficiency of $T$ cell recognition of the stimulator population, to a deficiency in the number of stimulator cells in the non-T cell population, or to an inherited or acquired alteration in the surface characteristics of the stimulator population. With regard to the nature of the stimulator cell, Kuntz et al. (2) have suggested that null cells are the major stimulator cells, while Sakane et al. (11) have provided evidence that $\mathrm{B}$ cells are the major stimulator cells. Recently, Beale et al. (17) using different techniques of cell isolation have shown that monocytes are the predominant stimulator cell type in the AMLR. Under the conditions used in our studies, we also found that the magnitude of the proliferative response in the AMLR was greatest when purified monocytes were used as the stimulators. With regard to the nature of the surface determinants on the stimulator cells, there is some evidence that the antigens responsible for the AMLR are closely related to the HLA-D locus (20), as well as evidence that the antigens responsible for the AMLR are distinct from those responsible for the MLR (21). Kuntz et al. (12) have found that the AMLR in three patients with SLE was normal when stimulator cells were obtained from MLR identical normal siblings. This finding suggests that the defective AMLR which has been observed in SLE is due to an abnormality of the stimulator population, rather than a defect of the $T$ cell population. Because patients with PBC have a number of immune abnormalities in common with patients with SLE, a similar mechanism might account for our findings in PBC, although other possibilities clearly must be excluded.

In conclusion, patients with $\mathrm{PBC}$ have a defective response in the AMLR. This defect may be related to the defect of generation of suppressor $T$ cell activity which has previously been described in this disease. Further understanding of the mechanism by which the AMLR occurs in normal subjects and in patients with abnormal immune responses may provide further insight into the pathogenesis of this as well as other autoimmune diseases.

\section{REFERENCES}

1. Opelz, G., M. Kiuchi, M. Takasugi, and P. I. Terasaki. 1975. Autologous stimulation of human lymphocyte subpopulations. J. Exp. Med. 142: 1327-1333.

2. Kuntz, M. M., J. B. Innes, M. E. Weksler. 1976. Lymphocyte transformation induced by autologous cells. IV. Human T-lymphocyte proliferation induced by autologous or allogeneic non-T lymphocytes. J. Exp. Med. 143: $1042-1054$.

3. Weksler, M. E., and R. Kozak. 1977. Lymphocyte trans- formation by autologous cells. V. Generation of immune memory and specificity during the autologous mixed lymphocyte reaction. J. Exp. Med. 146: 1833-1838.

4. Vande Stouwe, R. A., H. G. Kunkel, J. P. Halper, and M. E. Weksler. 1977. Autologous mixed lymphocyte culture reactions and generation of cytotoxic cells. $J$. Exp. Med. 146: 1809-1814.

5. Miller, R. A., and H. S. Kaplan. 1978. Generation of cytotoxic lymphocytes in the autologous mixed leukocyte culture. J. Immunol. 121: 2165-2167.

6. Smith, B. J., and R. Knowlton. 1979. Activation of suppressor $\mathrm{T}$ cells in human autologous mixed lymphocyte culture. J. Immunol. 132: 419-422.

7. Sakane, T., and I. Green. 1979. Specificity and suppressor function of human $\mathrm{T}$ cells responsive to autologous non-T cells. J. Immunol. 123: 584-589.

8. Abdou, N. I., A. Sagawa, E. Pascual, J. Hebert, and S. Sadeghee. 1976. Suppressor T-cell abnormality in idiopathic systemic lupus erythematosus. Clin. Immunol. and Immunopathol. 6: 192-199.

9. Bresnihan, B., and H. E. Jasin. 1977. Suppressor function of peripheral blood mononuclear cells in normal individuals and in patients with systemic lupus erythematosus. J. Clin. Invest. 59: 106-116.

10. Gerber, N. L., J. A. Hardin, T. M. Chused, and A. D. Steinberg. 1974. Loss with age in NZB-W mice of thymic suppressor cells in the graft-vs.-host reaction. J. Immunol. 113: 1618-1625.

11. Sakane, T., A. D. Steinberg, and I. Green. 1978. Failure of the autologous mixed lymphocyte reaction between $\mathrm{T}$ and non-T cells in patients with systemic lupus erythematosus. Proc. Natl. Acad. Sci. U. S. A. 75: 34643468.

12. Kuntz, M. M., J. B. Innes, and M. E. Weksler. 1979. The cellular basis of the impaired autologous mixed lymphocyte reaction in patients with systemic lupus erythematosus. J. Clin. Invest. 63: 151-153.

13. Smith, B. J., and R. D. Pasternak. 1978. Syngeneic mixed lymphocyte reactions in mice: strain distribution, kinetics, participating cells, and absence in NZB mice. J. Immunol. 121: 1889-1892.

14. James, S. P., C. O. Elson, E. A. Jones, and W. Strober. 1980. Abnormal regulation of immunoglobulin synthesis in vitro in primary biliary cirrhosis. Gastroenterology. 79: $242-254$.

15. Dienstag, J. L., J. R. Weake, and J. R. Wands. 1978. Abnormalities of lymphocyte regulation in primary biliary cirrhosis. Gastroenterology. 75: 960. (Abstr.)

16. Zetterman, R. K., and J. A. Woltjen. 1980. Suppressor cell activity in primary biliary cirrhosis. Dig. Dis. 25: 104- 107.

17. Beale, M. G., R. P. MacDermott, M. C. Stacey, G. S. Nash, B. H. Hahn, M. V. Seiden, S. L. Burkholder Jacobs, and L. S. Pletscher Lowenstein. 1980. Stimulating cell types in the autologous mixed leukocyte reaction in man. J. Immunol. 124: 227-232.

18. Jones, E. A., M. M. Frank, C. J. Jaffe, and J. M. Vierling. 1979. Primary biliary cirrhosis and the complement system. Ann. Intern. Med. 90: 72-84.

19. Wands, J. R., J. L. Deinstag, A. K. Bahn, E. R. Feller, and K. J. Isselbacher. 1978. Circulating immune complexes and complement activation in primary biliary cirrhosis. N. Engl.J. Med. 298: 233-237.

20. Hausman, P. B., and J. D. Stobo. 1979. Specificity and function of a human autologous reactive T cell. $J$. Exp. Med. 149: 1537-1542.

21. Smith, J. B. 1978. Stimulation of autologous and allogeneic human $\mathrm{T}$ cells occurs through separate B-cell antigen systems. Cell. Immunol. 36: 203-209. 